Orissa Journal of Commerce

Vol. 42, Issue 2, April-June 2021

ISSN: 0974-8482

(C) OJC India. All Right Reserved

URL: www.ojcoca.org

DOI: https://doi.org/10.54063/ojc.2021.v42i02.09

\title{
A Study on Work Environment, Work-life Balance and Burnout among Health Workers in Bangalore during COVID-19 Era
}

\author{
Kusuma H.S. ${ }^{*}$ and Shampa Nandi ${ }^{2}$ \\ ${ }^{1}$ Research Scholar, Perriyar University \& Assistant Professor, Swami Vivekananda Rural First Grade College, Bangalore, Karnataka. \\ E-mail: kusumamn321@gmail.com \\ ${ }^{2}$ Professor \& HOD, PGDM, International School of Management Excellence, Bangalore, Karnataka. \\ E-mail: shampanandi12345@gmail.com, \\ "Corresponding Author
}

To cite this paper

H.S., Kusuma., \& Nandi, S. (2021).

A Study on Work Environment, Work-life Balance and Burnout among Health Workers in

Bangalore during COVID-19 Era.

Orissa Journal of Commerce. 42(2),

109-124

Keywords

Healthcare workers, Work life balance, Stress and burnout, COVID-19, Work life climate factors, Workplace settings.

JEL Classification

I12, I31, J28, J81

\begin{abstract}
Recent outbreak of the global pandemic due to COVID-19 has led to a public health emergency, threatened human life and, created a worldwide economic challenge. Doctors, nurses and, health care workers from public and private sectors responded quickly to tackle the health crisis with stretched resources, shortage of personal protective equipment (PPE), and limited infrastructures. Physical exhaustion due to heavy workload, fear of getting infected, feeling powerless to handle a dying patient's condition and, lack of protective gears and infrastructures have created a situation of tremendous mental stress and high burnout among them. This empirical study investigated the sources of supports- the workplace and family and their impacts on the work-life balance based on a survey using pre-established constructs measured on the Likert scale on the healthcare professionals in Bangalore during November-December 2020. The result indicated that workplace settings have a significant impact on work-life balance (WLB). Unmarried women found to balance the work with less burnout and health workers at higher positions were supported in a better manner by the hospital management.
\end{abstract}

\section{Introduction}

WHO declared the novel coronavirus as a severe respiratory syndrome on 11 March 2020 with the publication of public health guidelines to reduce the rapid transmission of the deadly virus As a quick response, the Government of India treated it as a public health emergency and took several steps including lockdowns to get prepared to fight the pandemic and to stop the chain of infection of the extremely contagious virus through human transmission. During the lockdown, all the people were safe at home but the people who struggled by keeping the lives under risk were the health workers which include doctors, nurses, administration staff, housekeeping staff, paramedical staff, ward boys, and ambulance service personnel. Due to the pandemic, their lives were heavily disrupted due to the 
high level of work pressure and high level of stress. The mental well-being of the healthcare providers has been impacted due to erratic work schedules, physical exhaustion, feeling helpless in front of dying patients, fear of getting infected, and lack of protective gears and infrastructure. India has both government and private hospitals to render medical services. Due to the fear of the spread of viruses, private hospitals either shut their doors for the treatment or used to charge exorbitant bills, mostly unbearable by the public. On the other hand, at the initial stage of the pandemic, government hospitals were not well equipped to treat the patients (TOI, April 2, 2020). Despite that, due to the disease outbreak and to tackle the crisis, the health workers were forced to render the service without taking leaves. There were no exact medications to treat the Corona, using a PPE kit and protective gears were very uncomfortable at the beginning, and news on a continuous surge of cases and deaths of the general public and health care providers created extreme tensions and uncertainties among them (TOI, March 4, 2020). They have to undergo great pressure, stress, burnout, family issues, etc. Even after 15 months, the spread of the virus has not stopped and cases of new variants with higher rates of infection and mortality are spiking up. Situations became more stressful with the fear of their family members getting infected as well. Fortunately, the private hospitals started getting involved in treating the Corona patients and the vaccines started rolling. Doctors have been trying various combinations of available medications to treat based on the severity of the disease and at present reached a position to treat and cure the patients and able to reduce the death rate of the patients. Even in Bangalore, the COVID situation was handled well in the first wave by making necessary arrangements. But in the case of second-wave, there was less preparedness by the city which leads to a struggle for ICU beds for COVID patients and the city has observed a large number of deaths. Currently, the Health Ministry has formed a COVID 19 task force committee to predict 3rd wave situation and suggest for valuable solution. Considering the alarming guidelines BBMP prepared well to avoid the third wave and moving towards successful vaccination of the public (TOI September 29, 2021).

So, this paper has attempted to study the working conditions, work-life balance, burnout, and stress among health workers in continued COVID-era.

\section{Review of Literature}

A plethora of studies was carried towards the wellbeing of health workers across the globe. Some of these studies focused on understanding workplace challenges and fear of COVID, few concentrated on understanding mental and psychological stress, and few more made a study on the work-life balance of women employees especially.

The present study focused on three aspects- work environment, work life balance and burnout and a formal investigation on each terminology is essential to understand them better.

Work life balance (WLB) and work life integration (WLI) are interchangeably used by researchers and it describes the fact that the work schedule should leave enough time for personal and family life (Shanafelt et al., 2012). Due to the uncertain and erratic work schedule WLB of health care workers are always strained (Schwartz et al. 2019). A work setting is the office or workplace climate characterized by safety, communication, operational reliability and engagement. It also includes leadership style, organisation's readiness to change and team work culture present in any organisation (Profit et al., 
2014; Schwartz et al., 2017). A prolonged exposure to occupational stress which leads to a state of psychological, emotional and physical stress is called Burnout. (Maslach and Jackson, (1996). Emotional exhaustion, apathy towards patients and negative attitude towards professional accomplishments might be the resulting factors of burnout. Burnout causes serious health impacts among health care providers and they are poor health condition, lack of motivation and low morale (Dewa et al. 2017). Research showed that improper care to patients is given by high burnout medical professionals and there are other series consequences in the society (Dewa et al. 2017; Shanafelt et al. 2016).

Dasgupta (2012) made a study in Kolkata to understand how the role of overload, ambiguity, conflict impacts the work efficiency of nurses. It was found from the study that the factors overload, ambiguity and conflict made the nurses to disengage and exhausted. If they are self-efficient these factors can be easily managed. Shah et al., (2021) made a study in U.S. on burnout impact toward job turnover and it was found that major nurses had quit the job and those who are willing to quit is because of burnout which was led by 20 working hours in a week. If at all hospitals frame a proper strategy to reduce the working hours the problem may be resolved Ngoc et al., (2020) carried a study in Vietnam to assess the prevalence of occupational stress and found that there was an existence of occupational stress and it differs based on the nature of the job, age, qualification and so on. So, there is a need to the hospitals to analyze the reason for the stress at all the job levels to understand it in better manner otherwise it affects the hospital work. Niks et al. (2018) made a study in Dutch using a discovery method considering the three components job stress, job resources and detachment from job which was shown a positive impact on the employees who were involved in the study. Kieft et al., (2014) made a study in Dutch to understand the influence of patients experience on nursing staff and found that always the nurses were struggle in identifying the influencing factor of patient and fulfilling the work load requirement of hospital administration. Er and Sökmen (2018) investigated working conditions of nurses in public hospitals using nurse friendly hospital criteria. The investigation resulted that the nurses found to have friendly environment but pointed out that the proper hospital infrastructure should be organized and more involvement of nurses in the administrative activities will be an added advantage. Liu et al., (2020) has researched in China regarding the health care provider's experiences during the COVID-19 crisis. It was found that patients took maximum care with more responsibility to stop the spread of the virus. But with heavy workloads, fear of infection, and feeling powerless to handle dying COVID patients, health care providers faced a high level of stress. Another study was carried on by Mhango et al., (2020) on risk factors and occupational hazards of health workers in South Africa. It indicated that the major risk for health care workers was lack of protection equipment, treating infected patients, working long hours, etc. Kuo et al., (2020) in Taiwan attempted to understand perceived work stress among all categories of health workers. They found that nurses who were caring for infected patients faced more stress compared to the administrative and medical technicians. It showed that medical technicians had a higher degree of stress due to difficulties and anxieties on infection control.

Recent research was conducted in the USA by Aiyer (2020) on mental health and the impact of COVID-19 among health workers. Perceived stress of nurses and possibilities of depression and anxiety due to patients' health was studied by the researchers. It was found that registered nurses were 
faced major mental stress compared to the physicians and even the patients with COVID were found mostly depressed. Kansal (2020) empirically developed research in Nepal to understand mental health impact and found that anxiety, depression level has increased among health care workers in COVID era compared to pre COVID time. Depression also showed a higher impact on work performance. Li \& Miao et al., (2020) tried to understand the psychological impact on women employees during COVID; it was found that those who are working in isolation wards, women with more than one child are more psychologically impacted than the other women employees in hospitals. Vaghar and Masrour (2019) in Tehran tries to know about satisfaction and family conflict among married nurses with different working hours found that the women who work in rotating shifts were more satisfied and happy compare to women working in the morning shift. Marcinkus et al., (2006) carried on a study on the relationship of social support with work-family balance among middle-aged women and was able to identify that the women will get personal social support than work-based social support. If the organizational policies, social surroundings, and organizational environment render positive support women can easily balance both families and work with ease. Sexton et al., (2018) developed a Work-Life Integration Scale to study work-life balance behaviours cluster in work settings and relate to burnout and safety culture. The measure on a scale indicates that the work-life Integration differs among health workers based on the job position, work timing, etc., and also found that burnout and job dissatisfaction were more among them. If work place settings in the organization are positive it leads to better teamwork and safety climate.

Nelson (2010) tries to know work scheduling satisfaction and Work-Life Balance for Nurses. It was found that proper scheduling of work and positive perception towards work schedule will give satisfaction to nurses. Kansal (2020) in his study tries to identify the positive and negative impacts during COVID-19. The positive aspects identified were Family time, flexible working hours, vocational learning and focus on health and negative impact identified on working women like Workload, Monotonous routine, Stress and Bleak future aspects, etc. Vageha (2017) understands the maintaining the balance between health and work by comparing working women with non-working women. The non-working woman is healthier and having more than a kid but is denied financial freedom compared to the working women. Patil (2012) observed the prevailing infrastructure, working conditions, and policies in India. The study found that the numbers of working hours are more like 11 to 12 hours despite which no extra pay and personal benefits were provided to encourage the staff. Sowjanya et al., (2015) in the study Work Place Issues and Challenges Faced by Women Doctors in Clinical departments. The major challenges faced by women doctors in ate workplace were invisible hurdles, motherhood, lack of family support, career growth, failing to maintain the balance between career development and lifestyle. Dhadave et al., (2012) made a study on working problems among nursing staff. The main reason for a woman to work is to gain financial stability and identified the major problem while working is less health-conscious.

Existing works of literature were much focused on work-life balance, the psychological wellbeing of health care workers and working conditions, and the availability of proper infrastructures in the hospitals across the globe during the pandemic. Several pieces of research were carried on mental health and the impact of COVID-19, perceived work stress, traumatic experience of health care workers during COVID. 
Aiken et al., (2011) conducted a study in 9 different countries like South Korea, Japan, and Germany to understand the effect of the work environment on hospitals outcome. The poor work environment was commonly found in all observed countries which impacted much on hospital outcomes. Reith (2018) carried research in US to understand the burnout among healthcare professionals. It was found that those who were directly involved in caring for the patients were facing more burnout compare to other medical staff. In China, Japan, Taiwan, European countries, and the USA multiple studies are carried on the health care providers on the burnout issues and lack of work-life integration because of improper Workplace settings and Work-life climate during the COVID era.

Work-life balance, psychological well-being, workplace issues, mental health impact on Nurses, doctors, and other health care providers are very contemporary topics of research across the globe.

\section{Objectives and Hypotheses of the Study}

\subsection{Objectives of the Study}

In India, there is a dire need to research work-life balance, psychological well-being, workplace issues, mental health impact on nurses, doctors, and other health care providers as many studies are not observed so far. There is a scope to study the workplace challenges faced by health care workers during the COVID19 pandemic in India. Keeping this in view, the present study is designed to investigate the various sources of supports- both from workplace and family support and their impact on the work-life balance.

a) To analyse various dimensions of Workplace settings, Work-life climate provided by Hospitals during the COVID-19 era in terms of Safety norms (safe from infection, managing the COVID situation in the workplace, sanitation carried on in the hospital); Quality measures in a work setting (work adjustment \& co-operation from colleagues \& supervisors, number of working hours in a company, leaves facilities and flexible timing); and Work-life climate factors (disturbed sleep due to heavy work and stress, balancing work household and family, anxiety and anger varies because of work stress, time spent with family, timely consumption of food, other demographics factors).

b) To measure the impact of all the above-mentioned factors on work-life balance.

c) To assess the impact of demographic factors on the work-life balance of the health workers.

\subsection{Hypotheses of the Study}

Hypothesis 1: Work Place settings (Cooperation from Management, Training provided, PPE kit availability and usage, Cooperation from Patients and Family Support) affect the Work-life balance of healthcare professionals.

Hypothesis 2: Workplace settings (Cooperation from Management, Training provided, PPE kit availability and usage, Cooperation from Patients and Family Support) affecting the Work-life balance vary across demographics like gender, marital status, income, age, and qualification of the health care professionals. Hypothesis 3: Workplace settings (Cooperation from Management, Training provided, PPE kit availability and usage, Cooperation from Patients and Family Support) affecting the Work-life balance vary across public and private hospitals. 
Hypothesis 4: All the factors related to safety norms, workplace settings, work-life climate factors have a significant impact on the work-life balance of the health care professionals.

\section{Research Methodology}

Empirical research was done to measure the work-life balance and burnout of health care professionals in hospitals during the pandemic.

\subsection{Construct Building}

Constructs were built to measure cooperation from management, support from family, Training, Cooperation from Patients, and PPE kit utilization by various statements prepared on a 5-point Likert scale $(1=$ totally disagree and $5=$ totally agree). Work-life climate factors (disturbed sleep due to heavy work and stress, balancing work household and family, anxiety and anger vary because of work stress, time spent with family, timely consumption of food, etc.) were measured on a ten-point rating scale. Different literatures are reviewed and referred in this regard.

\subsection{Sampling and Sample Size}

Data was collected through the structured questionnaire in Google form as well as directly through the printed copies. The study population consisted of all level employees in both private and government hospitals in and around Bangalore. The researcher collected data from October to December 2020 from 123 respondents. A convenience sampling method was used.

\subsection{Analytical Tools}

T-test, ANOVA, Multiple Linear Regression was applied after checking its pre-testing assumptions to test the hypotheses. For regression assumptions, Chan (2004) and Panda et al., (2021) are being referred. Constructs are used for such analysis. Data was analysed using Excel and Python software.

\section{Data Analysis}

Table 1: Demographic Profile of the Respondents

\begin{tabular}{lrr}
\hline Variables & Frequency $(n=123)$ & Percentage \\
\hline Gender & 30 & \\
Male & 93 & $76 \%$ \\
Female & & \\
Age & 41 & $33 \%$ \\
$20-30$ & 53 & $43 \%$ \\
$31-40$ & 27 & $22 \%$ \\
$41-50$ & 2 & $2 \%$ \\
$50 \&$ above & & \\
Marital Status & 88 & $71 \%$ \\
Married & & contd. table 1 \\
\hline
\end{tabular}


A Study on Work Environment, Work-life Balance and Burnout among Health Workers in Bangalore

\begin{tabular}{lrr}
\hline & & \\
\hline Variables & Frequency $(n=123)$ & Percentage \\
\hline Unmarried & 35 & $29 \%$ \\
Designation & 13 & $11 \%$ \\
Doctors & 17 & $14 \%$ \\
Para-medical Staff & 43 & $35 \%$ \\
Nurse & 11 & $9 \%$ \\
Front Office & 33 & $26 \%$ \\
Office Administration & 6 & $5 \%$ \\
House Keeping & & \\
Type of Hospital & 41 & $34 \%$ \\
Government & 82 & $66 \%$ \\
Private & & \\
Qualification & 4 & $3 \%$ \\
SSLC & 5 & $4 \%$ \\
PUC & 45 & $37 \%$ \\
Diploma & 37 & $30 \%$ \\
Degree & 26 & $21 \%$ \\
PG & 6 & $5 \%$ \\
MD & & \\
Income (Monthly in Rs) & 41 & $33 \%$ \\
Less than 50 thousand & 29 & $24 \%$ \\
$50,000-1,50,000$ & 33 & $27 \%$ \\
$1,50,000-2,50,000$ & 11 & $9 \%$ \\
$2,50,000-3,50,000$ & 7 & $6 \%$ \\
$3,50,000-4,50,000$ & 2 & $1 \%$ \\
$4,50,000$ and above & & \\
\hline & &
\end{tabular}

Source: Authors' own calculation

Table 2: External Factors Influencing Work Life Balance: Descriptive Analysis

\begin{tabular}{lccl}
\hline Variables & Mean & Std. Dev. & Description \\
\hline $\begin{array}{l}\text { Cooperation from } \\
\begin{array}{l}\text { Management } \\
\text { Family Support }\end{array}\end{array}$ & 3.13 & 1.11 & $\begin{array}{l}\text { As the mean value is more than } 3 \text { it indicates that the majority of } \\
\text { the employees are getting support from management. } \\
\text { The mean value of family support is comparatively higher than the } \\
\text { other variables and it indicates there is manageable support from } \\
\text { the family to balance work and life. } \\
\text { The mean value indicates that the hospitals are taking little initiative } \\
\text { to train the employees towards managing stress. } \\
\text { The majority of the employees felt that they were } \\
\text { able to get a moderate level of support from patients. } \\
\text { As the mean value is more than 3 indicates that the employees } \\
\text { are a little uncomfortable to get PPE kit and its usage. }\end{array}$ \\
$\begin{array}{l}\text { Cooperation from } \\
\text { patients }\end{array}$ & 3.26 & 1.09 & 0.94 \\
$\begin{array}{l}\text { PPE Kit availability } \\
\text { and usage }\end{array}$ & 3.23 & 1.19 &
\end{tabular}

Source: Authors' own calculation

Orissa Journal of Commerce, 42(2) (C) 2021 


\subsection{Analysis of Factors of Work Place Settings Affecting the Work - life Balance}

$\mathrm{H}_{0}$ : Rating on factors related to Work Place Settings at Hospitals like Cooperation from Management, Training provided, PPE kit availability and usage, Cooperation from patients and Family support do not differ among healthcare professionals with good work-life balance vs. poor work-life balance.

Table 3: Analysis of Factors of Work Place Settings Affecting the Work - life Balance

\begin{tabular}{lllllc}
\hline Factors & \multicolumn{2}{c}{ Mean } & T-statistic & T-critical & $P$-value \\
\hline & Poor WLB & Good WLB & & & \\
\hline Co-operation from Management & 2.9 & 3.544 & -3.1854 & 1.6575 & $0.0009^{* *}$ \\
Support from family & 3.3160 & 3.501 & -1.552 & 1.6575 & $0.061^{* *}$ \\
Training & 3.045 & 3.651 & -3.0352 & 1.6575 & $0.001^{* *}$ \\
Co-operation from patients & 3.070 & 3.496 & -2.4441 & 1.6575 & $0.007^{* *}$ \\
PPE Kit & 3.067 & 3.527 & -2.2509 & 1.6592 & $0.013^{* *}$ \\
Mean of means & 3.0796 & 3.5438 & & & \\
\hline
\end{tabular}

Source: Authors' own calculation

The above table portrays that the overall average of employees who are not able to balance their work is less than that of those who can balance their work and life. The overall $\mathrm{P}$-value is less than the significant value so, the null hypothesis is rejected. There is a difference in co-operation of management, support from family, training to handle stress, Cooperation from patients, PPE kit utilization, etc. Schwartz (2018 has also indicated in his study that Lack of PPE, exposure to infected patients, work overload, and poor infection control are considered as the risk factors.

\subsection{Analysis of External Factors Affecting the Work- life Balance V/S Demographic Factors}

$\mathrm{H}_{0}$ : There are no significant differences between the external factors that lead to work-life balance across demographics like Gender, Marital Status, and Types of Hospitals.

Table 4: Analysis of External Factors Affecting the Work life Balance V/S Demographic Factors

\begin{tabular}{llllll}
\hline External factors & \multicolumn{2}{c}{ Mean } & Tstat & TCritical & P-Value \\
\hline Gender & Men & Women & & & \\
\hline Co-operation from Management & 3.65714 & 2.9539 & 3.1238 & 1.6575 & $0.00^{* *}$ \\
Support from family & 3.5857 & 3.3149 & 2.0557 & 1.6765 & $0.02^{* *}$ \\
Training & 3.7778 & 3.0896 & 3.9007 & 1.6643 & $0.00^{* *}$ \\
Co-operation from patients & 3.5444 & 3.1146 & 2.2148 & 1.6575 & $0.014^{* *}$ \\
PPE Kit & 3.81111 & 3.0394 & 3.2060 & 1.6575 & $0.00^{* *}$ \\
Mean of means & 3.67522 & 3.10248 & & & \\
\hline
\end{tabular}

contd. table 4 
A Study on Work Environment, Work-life Balance and Burnout among Health Workers in Bangalore

\begin{tabular}{llllll}
\hline Marital Status & Married & Unmarried & & & \\
\hline Co-operation from Management & 3.0665 & 3.2734 & -.1330 & 1.6603 & $0.12^{* *}$ \\
Support from family & 3.3717 & 3.4040 & -.2864 & 1.663 & $0.38^{* *}$ \\
Training & 3.1287 & 3.5809 & -2.7058 & 1.6585 & $0.00^{* *}$ \\
Co-operation from patients & 3.1856 & 3.3047 & -0.6335 & 1.6575 & $0.26^{* *}$ \\
PPE Kit & 3.0454 & 3.6444 & -2.413 & 1.658 & $0.00^{* *}$ \\
Mean of means & 3.15958 & 3.44148 & & & \\
\hline Types of hospital & Gov. & Private & & & \\
\hline Co-operationfrom Management & 2.445 & 3.465 & -5.30 & 1.657 & $.00^{* *}$ \\
Support from family & 3.090 & 3.526 & -3.77 & 1.657 & $0.00^{* *}$ \\
Training & 2.552 & 3.609 & -5.684 & 1.657 & $.00^{* *}$ \\
Co-operationfrom patients & 2.764 & 3.447 & -4.034 & 1.657 & $.00^{* *}$ \\
PPE Kit & 2.569 & 3.556 & -4.703 & 1.657 & $.00^{* *}$ \\
Mean of means & 2.684 & 3.5206 & & & \\
\hline
\end{tabular}

Source: Authors' own calculation

The table above reveals that significant differences are observed in all the external factors like Cooperation from Management, Support from Families, Training, Cooperation from Patients, PPE kit availability. Male rated higher in all the factors than females. So, male workers can balance their work better than female workers. Even Aiyer (2020) had also observed that the male is less stressed compared to female. Male can spend more time the work compares to females, as in the Indian social set up males are less responsible for household chores. Whereas women have to take care of family, children, and also to work with the fear of infection. Vageha (2017) observed that the working women get good support from family and enjoy financial independence.

Again, all external factors were rated significantly higher by unmarried health workers than married employees. Kuo et al., (2020) indicates that married women with young children were more stressed compare to unmarried women.

The comparison of external factors with the type of hospitals reveals the average mean score of private hospitals employees is more than government hospital employees which indicates that the private employees can get good support from management and family and even they are well trained to handle stress. Comparatively, government employees are not able to access the advanced equipment, working in the far location from their homes, and even the hospital infrastructure is not upgraded with the latest technologies and equipment. There is a difference in external factors influence on work-life balance of gender, marital status, and type of hospital.

\subsection{Impact of Demographic Factors on External Factors}

Anova is applied for such analysis. The hypothesis which is tested by applying anova is as follows. 
Kusuma H.S. and Shampa Nandi

$\mathrm{H}_{0}$ : There are no significant differences in external factors that lead to work-life balance across demographics variables like qualification, age, and income.

Table 5: Application of ANOVA to Process External Factors with the Demographic Factors

\begin{tabular}{|c|c|c|c|c|c|}
\hline External Factors & $S S$ & $D f$ & $M S$ & $F$ & $P$-value \\
\hline \multicolumn{6}{|l|}{ Qualification } \\
\hline \multicolumn{6}{|c|}{ Co-operation from Management } \\
\hline Between Groups & 22.88883 & 2 & 11.444 & 10.77791 & $.00 * *$ \\
\hline Within Groups & 127.4208 & 120 & 1.0618 & & \\
\hline \multicolumn{6}{|c|}{ Support from Family } \\
\hline Between Groups & 4.047103 & 2 & 2.0235 & 5.366868 & $0.00 * *$ \\
\hline Within Groups & 45.24541 & 120 & 0.37704 & & \\
\hline \multicolumn{6}{|l|}{ Training } \\
\hline Between Groups & 15.76088 & 2 & 7.88044 & 9.840301 & $0.00 * *$ \\
\hline Within Groups & 96.1 & 120 & 0.80083 & & \\
\hline \multicolumn{6}{|c|}{ Co-operation from Patients } \\
\hline Between Groups & 12.12932 & 2 & 6.06466 & 7.629442 & $0.00 * *$ \\
\hline Within Groups & 95.38829 & 120 & 0.79490 & & \\
\hline \multicolumn{6}{|l|}{ PPE Kit } \\
\hline Between Groups & 29.01034 & 2 & 14.5051 & 12.12937 & $0.00 * *$ \\
\hline Within Groups & 143.5046 & 120 & 1.19587 & & \\
\hline \multicolumn{6}{|l|}{ INCOME GROUP } \\
\hline \multicolumn{6}{|c|}{ Co-operation from Management } \\
\hline Between Groups & 4.476026 & 2 & 2.23801 & 1.841562 & 0.16 \\
\hline Within Groups & 145.8336 & 120 & 1.21528 & & \\
\hline \multicolumn{6}{|c|}{ Support from Family } \\
\hline Between Groups & 3.542698 & 2 & 1.77134 & 4.64618 & $0.01 *$ \\
\hline Within Groups & 45.74982 & 120 & 0.38124 & & \\
\hline \multicolumn{6}{|l|}{ Training } \\
\hline Between Groups & 13.08057 & 2 & 6.54028 & 5.956239 & $0.00 * *$ \\
\hline Within Groups & 131.7668 & 120 & 1.09805 & & \\
\hline \multicolumn{6}{|c|}{ Co-operation from Patients } \\
\hline Between Groups & 16.52772 & 2 & 8.26385 & 10.89861 & $0.00^{* *}$ \\
\hline Within Groups & 90.9899 & 120 & 0.75824 & & \\
\hline \multicolumn{6}{|l|}{ PPE Kit } \\
\hline Between Groups & 10.2213 & 2 & 5.11065 & 3.778819 & $0.03^{* *}$ \\
\hline Within Groups & 162.2936 & 120 & 1.35244 & & \\
\hline
\end{tabular}

contd. table 5 
A Study on Work Environment, Work-life Balance and Burnout among Health Workers in Bangalore

\begin{tabular}{llllll}
\hline External Factors & $S S$ & Df & $M S$ & $F$ & $P$-value \\
\hline Age & & & & & \\
Co-operation from Management & & & & & \\
Between Groups & 0.880940 & 2 & 0.44047 & 0.353724 & 0.71 \\
$\begin{array}{l}\text { Within Groups } \\
\text { Support from Family }\end{array}$ & 149.4286 & 120 & 1.24523 & & \\
$\begin{array}{l}\text { Between Groups } \\
\text { Within Groups }\end{array}$ & 0.069777 & 2 & 0.03488 & 0.085055 & 0.92 \\
Training & 49.22273 & 120 & 0.41018 & & \\
Between Groups & & & & & \\
Within Groups & 7.401171 & 2 & 3.70058 & 3.230867 & $0.04 *$ \\
Co-operation from Patients & 137.4461 & 120 & 1.14538 & & \\
Between Groups & & & & & \\
Within Groups & 0.169478 & 2 & 0.08473 & 0.094726 & 0.91 \\
PPE Kit & 107.3481 & 120 & 0.89456 & & \\
$\begin{array}{l}\text { Between Groups } \\
\text { Within Groups }\end{array}$ & 4.268710 & 2 & 2.13435 & 1.461632 & 0.23 \\
\hline
\end{tabular}

Source: Authors' own calculation

From the Table 5, it is clear that when we observe the qualification with the external factors the overall P-value is less than the significant level. This indicates the null hypothesis is rejected. So, there is a relationship between the qualification and external factors. Higher the qualification higher will be the job position and more will be the support from the management, more safety will also be provided. When we look at the comparison of income and external factors P-value is more than significant level only in case of co-operation from management but the other factors it's less than significant level, which indicates that higher salaried employees are getting good support from the management and from family to some extent compared to the slightly low income generated employees. In a similar comparison of age and external factors, P-value is more than the significant level so, the null hypothesis is accepted. Based on age there is no difference in co-operation of management, support from family, training, PPE kit utilization towards the employees.

\subsection{Correlating Workplace Settings, Work Life Climate Impact and Health Worker's Work Life Balance}

The following hypothesis is tested for tracing the relationship among these factors.

$\mathrm{H}_{0}$ : All the factors related to Safety norms (safe from infection, managing the COVID situation in the workplace, sanitation carried on in the hospital), quality measures in a work setting(work adjustment \& co-operation from colleagues \& supervisors, number of working hours in a company, leaves), as well as work-life climate factors (disturbed sleep due to heavy work and 
stress, balancing work household and family, anxiety and anger varies because of work stress, time spent with family, timely consumption of food, other demographics factors), have equal impact on the Work-life Balance of health care workers.

\section{Bivariate Correlation among all the factors}

Heatmap shows the relationship between variables and it is observed that safety, sanitation, COVID management at workplace, working hours, and colleagues have high correlation with WLB.

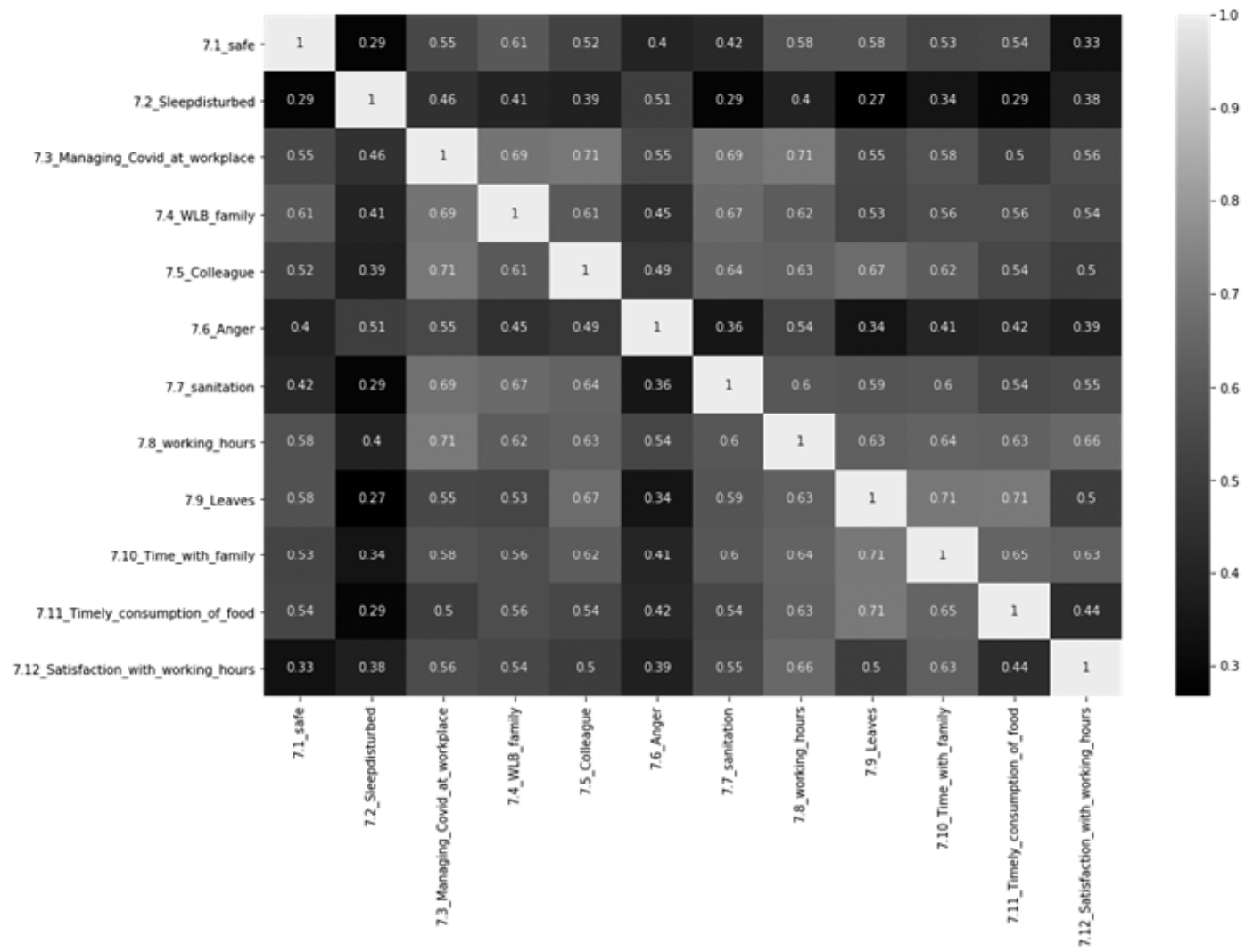

Figure 1: Heatmap; Bivariate Correlation

Source: Authors' own calculation

\subsection{Factors Impacting Work Life Balance}

Regression model is applied for assessing the quantum of impact of deferent factors on work life balance. R square value of the model is 0.65 which depicts that all independent variables together have $65 \%$ explaining efficiency in the model. All other assumptions of regression model are quite satisfactory. 


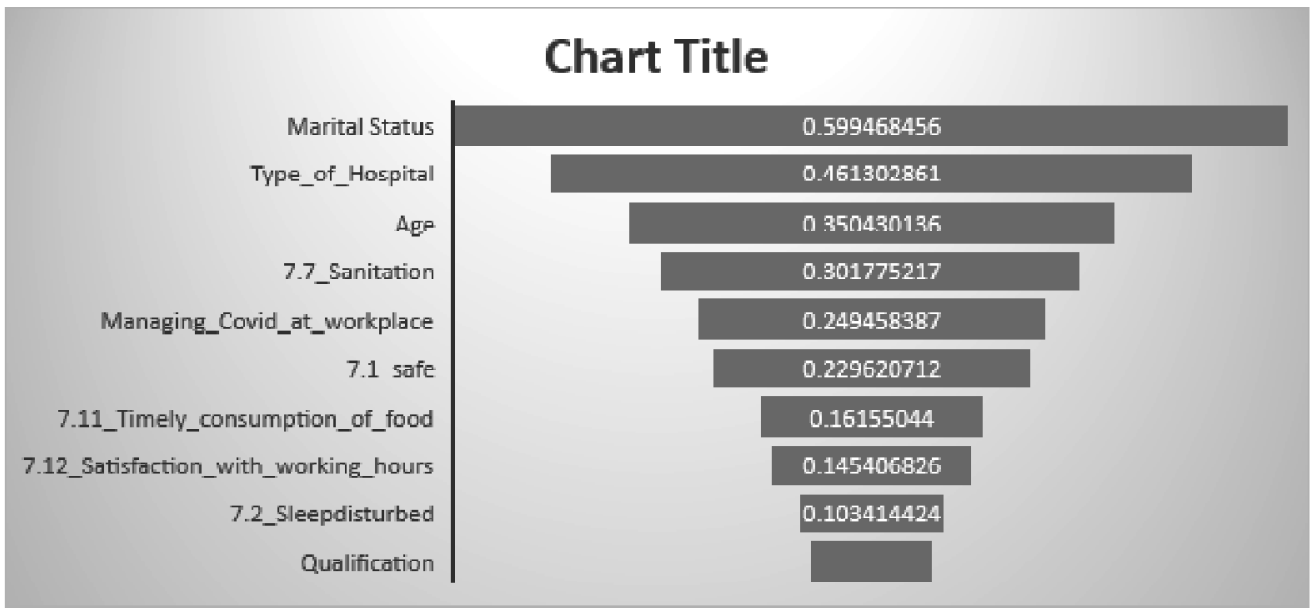

Figure 2: Regression Predictors

Source: Authors' own calculation

The figure above traced that Martial Status makes a lot of difference in WLB, primarily because of dual responsibilities at both work and home for a married person. Type of hospital whether Government or private is another significant factor in influencing WLB. The age of the healthcare worker plays an important role in work-life balance. Quality measure at work settings which includes Sanitation, Safety, and COVID Management has been associated with WLB. Linkage was found between work-life climate factors namely timely consumption of food, working hours, and sleep with WLB.

\section{Conclusion and Managerial Implications}

Doctors, nurses, and health care workers from both Government and private hospitals responded quickly to tackle the health crisis due to COVID 19 in Bangalore with stretched resources, shortage of personal protective equipment (PPE), and contributed to the maximum possible to overcome the challenges. They are the frontline warriors with an extraordinary sense of responsibility who have been serving humanity relentlessly by keeping their own lives at risk.

Current study based in Bangalore indicated that factors related to Work Place Settings at Hospitals (Cooperation from Management, Training provided, PPE kit availability and usage, Cooperation from Patients) and Family Support have a significant impact on the Work-life balance of Health care professionals. Ratings on all the above factors are significantly higher among healthcare professionals with good work-life balance than those with poor work-life balance (Schwartz, 2018).

All the above factors vary among Health care professionals across different qualifications. It seems qualified professionals might receive better treatments in the workplace.

Aiyer (2020) stated that since healthcare workers at all levels are equally exposed to the Coronavirus, hospitals should ensure equal treatment, providing safety equipment and cooperation from management to employees irrespective of their designations. 
Gender, Marital status (Vaghar and Masrour, 2019) and Age play a very important role in Worklife balance; as they have shown the highest impact. Another very important factor is the Types of hospitals. Employees from private hospitals used to get good support from management as well as training to handle stress.

Safety norms, quality measures in a work setting (Marcinkus et al., 2006), and work-life climate factors together have around 65\% impact on the WLB of the health workers.

COVID-19 has indeed created a lot of anxiety and uncertainties among health care professions. Several studies around the globe have investigated the high stress, burn out and other psychological impacts of the pandemic on health workers, and several programs are organized on stress management, mindfulness, and wellbeing. Both hospitals and the government need to take much more initiatives to protect the front-line warriors. Support and encouragement from Hospitals and Society should not be discriminant based on the position of health care professionals.

\section{Limitation and Future Scope of the Study}

The strength of the present study lies in understanding various components of the Work-life balance of health care professionals and the recent challenges faced by them due to prolonged pandemics starting 2020. One limitation of the study is the sampling method, which is convenience sampling, a non-probability sampling method. Since for any non-probability sampling, generalization of the result could be an issue, future researchers can make use of some probability sampling, especially stratified sampling to get the representation of health care professionals at all levels. Larger sample size would give more generalized research outcomes. Future researchers should attempt to make the research area more comprehensive by adding additional predictors and influencers impacting work-life balance. This paper did not consider the intrinsic motivation of the doctors, nurses which motivate them to work relentlessly despite their life risks. Research could be conducted to check whether individual engagement with a job, sense of duties, and responsibilities of doctors, nurses, and other health care professionals make significant differences in their performance and work-life balance or not. The medical profession is a very noble profession; further study may demonstrate various other motivators influencing the medical professionals to be motivated all the time. This research also sheds some light on a comprehensive understanding of workplace settings and workplace climate factors and how do they differ between private and public hospitals and between different designations in the health care sector. This study is focused only on Bangalore and therefore to get a holistic view on the current situation of workplace setting, work life balance and burnout of the health workers, there is a huge scope to conduct the study in the rest of the country.

\section{References}

Aiken, L. H. DM, Sloane, D. M., Clarke, S., Poghosyan, L., Cho, E., You, L., Finlayson, M., Kanai-Pak, M., \& Aungsuroch, Y. (2011). Importance of work environments on hospital outcomes in nine countries. International Journal for Quality in Health Care, 23(4), 357-364. https:/ / doi.org/10.1093/intqhc/mzr022

Aiyer, S. (2020). Mental health impact of COVID-19 on healthcare workers in the USA: A cross-sectional webbased survey. Journal of Depression and Anxiety, 9, 373. https://doi.org/10.35248/2167-1044.20.9.373 
A Study on Work Environment, Work-life Balance and Burnout among Health Workers in Bangalore

Chan, Y. H. (2004) Biostatistics 201: Linear Regression Analysis. Singapore Med J, 2004; 45(2), 55-61.

Dasgupta, P. (2012). Effect of role ambiguity, conflict and overload in private hospitals' nurses' burnout and mediation through self-efficacy. Journal of Health Management, 14(4), 513-534. https://doi.org/10.1177/ 0972063412468980

Dewa, C. S., Loong, D., Bonato, S., \& Trojanowski, L. (2017). The relationship between physician burnout and quality of healthcare in terms of safety and acceptability: A systematic review. BMJ Open, 7(6), e015141. https:/ /doi.org/10.1136/bmjopen-2016-015141

Dhadave M. M., Kumar, A. G., Reddy, S., Rajshekar, K., \& Vijayanth, V. (2012). A study on work related problems among nursing staff. Journal of Pharmaceutical and Biomedical Science, 19(14), 34-44.

Er, F., \& Sökmen, S. (2018). Investigation of the working conditions of nurses in public hospitals on the basis of nurse-friendly hospital criteria. International Journal of Nursing Sciences, 5(2), 206-212. https://doi.org/10.1016/ j.ijnss.2018.01.001

https:/ / timesofindia.indiatimes.com//city/delhi/take-it-or-leave-it-price-of-masks-jacked-up-in-city/articleshow/ 74466555.cms.

https://timesofindia.indiatimes.com/city/bengaluru/karnataka-no-sign-of-third-COVID-wave-so-far-butdoctors-warn-against-complacency/articleshow/86602155.cms.

Kansal, K. (2020). Qualitative analysis of COVID-19 on working women. International Journal of Scientific and Research Publications, 10(6), 41-44. https://doi.org/10.29322/IJSRP.10.06.2020.p10208

Khanal, P., Devkota, N., Dahal, M., Paudel, K., \& Joshi, D.. (2020). Mental health impacts among health workers during COVID-19 in a low resource setting: A cross-sectional survey from Nepal. Globalization and Health, 16(1), 89. https://doi.org/10.1186/s12992-020-00621-z'

Kieft, R. A., de Brouwer, B. B., Francke, A. L., \& Delnoij, D. M. (2014). How nurses and their work environment affect patient experiences of the quality of care: A qualitative study. BMC Health Services Research, 14, 249. https://doi.org/10.1186/1472-6963-14-249.

Kuo, F. L., Yang, P. H., Hsu, H. T., Su, C. Y., Chen, C. H., Yeh, I. J., Wu, Y. H., \& Chen, L. C. (2020). Survey on perceived work stress and its influencing factors among hospital staff during the COVID-19 pandemic in Taiwan. Kaohsiung Journal of Medical Sciences, 36(11), 944-952. https://doi.org/10.1002/kjm2.12294'

Liu, Q., Luo, D., Haase, J. E., Guo, Q., Wang, X. N., Liu, S., Xia, L., Liu, Z., Yang, J., \& Yang, B. X., (2020). The Experience of health-care providers during COVID-19 crisis in China: A Qualitative Study. The Lancet Global Health, 8, 790-798. https:/ / doi.org/10.1016/S2214-109X(20)30204-7

Li, G., Miao, J., Wang, H., Xu, S., Sun, W., Fan, Y., Zhang, C., Zhu, S., Zhu, Z., \& Wang, W.' (2020). Psychological impact on women health workers involved in COVID-19 outbreak in Wuhan: A cross-sectional study. Journal of Neurology, Neurosurgery, and Psychiatry, 91(8), 895-897. https://doi.org/10.1136/jnnp-2020-323134'

Maslach, C., \& Jackson, S. E. (1981). The measurement of experienced burnout. Journal of Organizational Behavior, 2(2), 99-113. https://doi.org/10.1002/job.4030020205

Marcinkus, W. C., Whelan-Berry, K. S., \& Gordon, J. R. (2007). The relationship of social support to the workfamily balance and work outcomes of midlife women. Women in Management Review, 22(2), 86-111. https:// doi.org/10.1108/09649420710732060

Mhango, M., Dzobo, M., Chitungo, I., \& Dzinamarira, T. (2020). COVID-19 risk factors among health workers: A rapid review. Safety and Health at Work, 11(3), 262-265. https://doi.org/10.1016/j.shaw.2020.06.001

Orissa Journal of Commerce, 42(2) (C) 2021 
Nelson, T. (2010). Work scheduling satisfaction and work life balance for nurses: the perception of organizational justice. Academy of Health Care Management Journal, 6, 25-36.

Niks, I., de Jonge, J., Gevers, J., \& Houtman, I. (2018). Work stress interventions in hospital care: Effectiveness of the Discovery method. International Journal of Environmental Research and Public Health, 15(2). https:// doi.org/10.3390/ijerph15020332

Panda, P., Mishra, S., \& Behera, B. (2021). Developing a Research Methodology with the Application of Explorative Factor Analysis and Regression. IOSR Journal of Business and Management (IOSR-JBM), 23(04), 23-34.

Patil, S. (2012). A study of Working Conditions in the hospitals of Satara City. Journal of Organization and Human Behaviour, 1(1), 34-44.

Reith, T. P. (2018). Burnout in United States healthcare professionals: A narrative review. Cureus 10(12), e3681. https://doi.org/10.7759/cureus.3681

Sexton, J. B., Schwartz, S. P., Chadwick, W. A., Rehder, K. J., Bae, J., Bokovoy, J., Doram, K., Sotile, W., Adair, K. C., \& Profit, J. (2017). The associations between work-life balance behaviours, teamwork climate and safety climate: Cross-sectional survey introducing the work-life climate scale, psychometric properties, benchmarking data and future directions. BMJ Quality and Safety, 26(8), 632-640. https://doi.org/10.1136/bmjqs-2016006032

Shanafelt, T. D., Boone, S., Tan, L., Dyrbye, L. N., Sotile, W., Satele, D., West, C. P., Sloan, J., \& Oreskovich, M. R. (2012). Burnout and satisfaction with work-life balance among US physicians relative to the general US population. Archives of Internal Medicine, 172(18), 1377-1385. https://doi.org/10.1001/ archinternmed.2012.3199

Shanafelt, T. D., Dyrbye, L. N., West, C. P., \& Sinsky, C. A. (2016). Potential impact of burnout on the US physician workforce. Mayo Clinic Proceedings, 91(11), 1667-1668. https://doi.org/10.1016/j.mayocp.2016.08.016

Shah, M. K., Gandrakota, N., Cimiotti, J. P., Ghose, N., Moore, M., \& Ali, M. K. (2021) Prevalence of and Factors Associated with Nurse Burnout in the US. JAMA Network Open, 4(2), e2036469. https://doi.org/10.1001/ jamanetworkopen.2020.36469

Sowjanya, J. K., Geethalakshmi, S, Chandrashekaran, P. A., \& Bindhu. C. (2015). Work Place Issues and Challenges Faced by Women Doctors in Clinncal Departments. Journal of Dental and Medical Sciences 14.11 (2015): 51-61.

Vageha, M. (2017). Women, Work and health: A Pilot Study. Int. J. Preven. Curat. Comm. Med,3 (1\&2) 69-76. https://doi.org/0000-0001-7839-7501

Vaghar, M. I., \& Masrour, M. J. (2019). A comparative study of satisfaction and family conflicts among married nurses with different working hours. Journal of Family Medicine and Primary Care, 8(2), 472-476. 